\title{
Formation of Performance Indicators of System- forming Regional Enterprises under Uncertainty
}

\author{
Alexander Ivanus ${ }^{1}$, Victor Nevezhin ${ }^{2 *}$, Elena Piskun ${ }^{3}$, and Vladimir Khokhlov ${ }^{3}$ \\ ${ }^{1}$ Financial University under the Government of the Russian Federation, 125993 Moscow, Russia \\ ${ }^{2}$ Financial University under the Government of the Russian Federation, 125993 Moscow, Russia, \\ ${ }^{3}$ Sevastopol State University, 299053 Sevastopol, Russia
}

\begin{abstract}
A modern enterprise must be ready for any changes that may arise under the influence of both internal and external influences, including uncertain ones. It must be able to get out of this unfavorable situation as quickly as possible. The proposed study is to confirm the hypothesis of the relationship between the level of uncertainty and the performance of an enterprise based on the use of the preventive preparedness regime. The work solves the following tasks: assessment of the level of uncertainty of the external environment, selected as an indicator of entropy; a methodology for choosing the financial and economic indicators of an enterprise for the formation of a preventive readiness mode is proposed; the existence of a relationship between the level of uncertainty and indicators of the preventive readiness regime has been empirically confirmed. The authors propose a variant of the enterprise's transition to a state of so-called "maximum readiness", in which it will feel "comfortable". The concept of enterprise management in a situation of external uncertainty is presented. In accordance with this approach, the results of the analysis of financial, economic and social indicators of economically significant automobile enterprises located in various regions of Russia, included in the list of backbone and influencing the development of the region, have been investigated. The selected indicators were considered from the point of view of the possibility of applying to them the state of the maximum readiness mode in conditions of uncertainty, which provides an adaptive state of the enterprise and, accordingly, will allow maintaining and even increasing its position in the market in the presence of uncertainties. The proposed concept can be recommended to all firms and enterprises with an innovative focus since they are more susceptible to the adverse effects of uncertainties.
\end{abstract}

\section{Prodrome}

Nowadays it is difficult to imagine the life of the population without the use of cars. Many individuals may own more than one car. The variety of automotive enterprises in the world and the globalization of the economy have led to the fact that each person, depending on their earnings, is able to choose the most suitable model of vehicles produced in any country.

\footnotetext{
*Corresponding author: VPNevezhin@fa.ru, NVP1048@mail.ru
} 
Automobile enterprises, both around the world and in our country, are faced with the task of how to win and maintain consumer demand for their products. This strategy leads to constant competition between them. At the same time, the automotive market is influenced by many factors of uncertainty, as well as random ones, including such as the presence of an economic crisis, instability of the banking system, currency surges, changes in society, reforms, mergers and acquisitions of enterprises, re-profiling of enterprises themselves or their allies, the emergence of new and the closure of old enterprises, the attitude of consumers to the new assortment, as well as the influence of what has manifested itself at this time - a viral pandemic, etc.

All of these factors can be attributed to any enterprise. Therefore, in order to be as ready for them as possible in the current situation, the article proposes to use a specially developed mode called the preventive readiness mode (PRG) [1].

- The purpose of this study is to confirm the hypothesis of a relationship between the level of uncertainty and the performance of an enterprise based on the use of a preventive readiness mode. The following tasks are solved in the work:

- assess the level of uncertainty of the external environment, choosing the entropy indicator as its value;

- propose a way to select the financial and economic indicators of the enterprise for the formation of indicators of the PWG;

- to confirm empirically the existence of a relationship between the level of uncertainty and the indicators of the PWG.

-The implementation of these tasks will be further considered on the example of socially and economically significant automobile enterprises located in different regions of Russia. The studied enterprises are included in the list of backbone, are city-forming and have a significant impact on the development of the region.

- In this case, the implementation of an algorithm of actions is assumed, including the following sections:

- structuring indicators from annual reports of real automobile enterprises into separate tables as input data for research;

- form, on the basis of these data, financial and economic indicators for the PWG;

- on the basis of the chosen entropy indicator, to estimate the dynamics of the growth of the level of uncertainty;

- to analyze the dynamics of the aspiration of the financial and economic indicators of each enterprise, depending on the level of uncertainty;

- to develop recommendations for enterprises in terms of the formation of their financial and economic indicators, depending on the level of uncertainty.

\section{Theory}

Uncertainty is a permanent condition for the activity of economic agents of various types of activity and industry affiliation. Analysis of the practice of designing mining enterprises in conditions of uncertainty [2] showed that the procedure for substantiating design solutions and parameters of technological systems of coal mining should be approached from the standpoint of intelligent integrated methodologies. The article [3] considers uncertainty as one of the risk factors for the functioning of peasant farms, considers the tendencies of the development of small business in agriculture and suggests options for making managerial decisions to improve their efficiency; transformational changes in the agricultural sector in the context of institutional transformations are disclosed in [4]; the authors of [5] propose a methodological approach to assessing investments that support the economic development of agricultural enterprises in an uncertain competitive environment. 
The problem under consideration also applies to the service sector, when their activity is influenced by the uncertainty of the choice of users [6]. The increased uncertainty in the context of a pandemic jeopardize the activities of small enterprises, especially in health care, therefore in their work the authors of [7] analyze financial programs and resources that can help to cope with the crisis.

The analysis of the methods used for assessing the effective performance of enterprises in conditions of uncertainty made it possible to grade the existing economic and mathematical models of the formalized description of uncertainty according to the degree of its increase [8]. Management of financial and economic indicators of enterprises in conditions of growing uncertainty is proposed to be carried out based on economic and mathematical models of varying complexity, including: the scenario method [9], hierarchical regressions [10], optimization models [11, 12], the method of analysis of behavioral characteristics [13].

A preventive readiness mode (hereinafter - PWG) is a pre-developed plan of action in conditions of exceeding a certain critical level of uncertainty. Thus, with the onset of unforeseen changes in the external environment, the enterprise passes to management according to the PWG, which allows it to get out of the period of these changes, maintaining the "status quo", while improving or slightly deteriorating its market indicators, thereby the PWG is a tool for ensuring sustainable development companies in the face of market uncertainty. The PWG is not responsible for the development of the enterprise, since strategic management is responsible for this [14]. At the same time, the PWG helps the enterprise to develop - by overcoming negative consequences, emerging or existing uncertainties. In essence, the PWG is a short-term management event. In this case, it seems appropriate to consider it an element of strategic management.

\section{Data and Methods}

In accordance with the recommendations set forth in $[15 ; 16]$, the financial and economic indicators of enterprises in conditions of uncertainty are advisable to choose in accordance with the well-known Fibonacci ratio of 0.62: 1, the meaning of which is that the whole (taken as a unit) is the sum two unequal parts $(0.62$ and 0.38$)$, and this ratio is harmonious. The harmonious Fibonacci ratio is calculated from the sequence of a number of his numbers [17]:

$$
a_{n}=a_{n-1}+a_{n-2}
$$

as the limit of the ratio of two adjacent numbers $a_{n-1}$ and $a_{n}$ :

$$
\lim \left(\frac{a_{n-1}}{a_{n}}\right)=0,618: 1 \approx 0,62: 1 \text { при } \mathrm{n} \rightarrow \infty
$$

From a simple Fibonacci ratio of 0.62: 0.38 , an infinitely divisible family of proportions can be obtained using the same recursive algorithm for dividing the obtained values in a ratio of 0.62: 0.38 .

Fibonacci levels in the markets are calculated as follows:

The first level is conventionally equal to 1 (one);

Second level $=1 * 0.62=0.62 ;(0.62$ is the Fibonacci constant $)$;

Third level $=0.62 * 0.62=0.38$ :

Fourth level $=038 * 0.62=0.24$

Fifth level $=0.24 * 062=0.14$

etc., multiplying the value of each previous level by the Fibonacci constant of 0.62 , we obtain the value of the next level. 
The obtained indicators of the PRG are evaluated for proximity to the values of the Fibonacci levels, which is carried out only if the level of external market uncertainty increases. This trend is observed, for example, in all foreign exchange and stock markets and, in particular, on the so-called Elliott waves [18], which have been known since the 30s of the 20th century. Fibonacci switching points are the most convenient for the manifestation of maximum dynamic properties, which are extremely necessary to ensure the stability of market processes in the face of market uncertainty.

When the management of the enterprise receives additional information that removes external uncertainty, then the management of the enterprise from the PWG returns to the usual classical methods. Financial and economic parameters take on those values that are obtained as a result of solving optimization control problems. This continues until some new crisis or chaos occurs again, accompanied by a lack of knowledge about further actions, and then the company returns to management according to the PWG method.

\subsection{Formation of financial and economic indicators in the PWG mode}

In order for an enterprise to be able to make the transition from normal functioning to the point of maximum readiness, it is necessary to choose the set of indicators that would most fully characterize its activities, have a small volume and would be presented in open sources.

As such indicators, we have selected the data of financial and accounting statements, which are present for both domestic and international enterprises. This data in a compact form contains the following information about the company:

- internal resources (assets and current assets),

- finance (own and borrowed funds),

- economic activity (net profit)

- market relationship with the external environment (revenue).

This dataset allows you to build an assessment system for conducting analytical studies among a wide range of enterprises and use it to form the point of maximum readiness of the economic system in conditions of uncertainty.

As a result of the studies carried out for the PWG regime, it is proposed to apply the following set of indicators based on the initial data of financial and accounting statements:

$\mathrm{CP} / \mathrm{SK}$ - the ratio of net profit to equity;

$\mathrm{K} \phi y=\mathrm{SK} / \mathrm{A}-$ financial stability ratio, as the ratio of the amount of borrowed capital to the amount of total capital;

$\mathrm{OA} / \mathrm{A}$ - the ratio of current assets to the sum of all assets;

$\mathrm{CP} / \mathrm{Vyr}$ - the ratio of net profit to revenue;

$(\mathrm{Vyr}-\mathrm{A}) / \mathrm{A}$ - the ratio of the difference between revenue and assets to assets.

This set of financial and economic indicators reflects the economic potential of the enterprise, characterizes its efficiency and uniquely determines the behavior in the market. It is small, which simplifies the process of its analysis and use in practice and is also selected from open sources of financial and accounting statements of any enterprise.

\subsection{Model for assessing the level of external uncertainty}

When unexpected events occur that strongly affect the industry or the economic situation in general, and they often cause uncertainty. The term "uncertainty" is more often found where there are attempts to explain the qualitative changes taking place in the economy, and primarily in its innovation component [19]. To a certain extent, these changes are associated with the presence of crisis situations that generate uncertainty and lead to a decrease in the rate of economic growth of the enterprise. At the same time, the development of the enterprise is inhibited, which is the result of a natural cognitive subconscious search by the management 
of a certain state of maximum readiness of the economic system to work in conditions of maximum uncertainty, i.e. inhibition is a purely human response to uncertainty. Thus, the slowdown occurs not because some forces appear that oppose the natural course of development, but because in the emergence of such a situation, the leadership does not know where to "rule". Then, just in case, management slows down development, so that, due to ignorance of the situation, it does not fall on a false trajectory of development. As a result, we get a vicious circle, the exit from which requires the presence of maximum dynamic qualities that can be achieved at the points determined by the Fibonacci ratios.

To consider the main factors of uncertainty, it is necessary to first analyze the industry, since uncertainty is closely related to the economic situation in the industry and in the world.

As a measure of uncertainty, it is proposed to use such an indicator widely known in modeling practice as the value of entropy $\mathrm{H}$ [19]. Its choice is since it allows one to relate the entropy $\mathrm{H}$ with some of the parameters of the input and output flows that can be described by the Verhulst equation [20].

In general, the Verhulst differential equation has the form:

$$
\frac{d H(t)}{d t}=\lambda(t) \cdot H(t)-\rho(t) \cdot H^{2}(t)
$$

where $H(t)$ - output value of entropy of some system;

$\lambda(\mathrm{t})$ - variable amount of flow entering the system;

$\rho(t)$ - variable amount of flow leaving the system.

Here we are talking about the fact that the system and its state of uncertainty is defined as the result of both competitive and at the same time multidirectional impact on the system of input and output streams.

The result of such a competition is reflected in the value of the entropy $H$. The input stream increases the entropy of the system, and the output stream decreases. The analogs of input and output flows in the economy are such fundamental concepts as supply and demand.

If we consider the system under consideration in a stationary state, then the variables characterizing its state do not change with time and stationary points will be determined from the condition

$$
\frac{d H}{d t}=0
$$

One of these points will correspond to zero entropy, and the rest will be the roots of the equation:

$$
\lambda(t)-\rho(t) \cdot H=0
$$

If function $f(H)=\lambda-\rho \cdot H$ if the function is monotonic, then there is one nontrivial stationary point for it, the value of which is defined as

$$
H=\frac{\lambda}{\rho},
$$

and if not, then there may be several stationary points.

The multiplicity of solutions in a nonlinear system can be viewed as the gradual emergence of its autonomy in relation to the environment. 
From the functional definition of entropy (measure of order) it follows that the function is always positive, and, obviously, it is impossible to reach its stationary state if $\frac{\lambda}{\rho}<0$. Therefore, only stationary states will be physically reasonable when $H=\frac{\lambda}{\rho}>0$.

To assess the uncertainty of the economic system, in this case a manufacturing enterprise, equation (3) is transformed to the form:

$$
\frac{d H}{d t}=P_{o n p} \cdot H-B_{p} \cdot H^{2}
$$

where $R_{\text {opr }}$ is the company's operating expenses,

$\mathrm{B}_{\mathrm{P}}$ is sales revenue.

The choice of indicators $R_{o p r}$ and $B_{p}$ is due to the fact that they most fully reflect the essence of the studied state of the system. So, the value of Popr reflects the total costs of managing the enterprise, and the value of $B_{p}$ - its financial result.

Then the meaning of the above equation (7) will be as follows. Operating expenses are the costs of running an enterprise, and the result of management is revenue. It is easy to understand that if we spend a lot of money on management, and the revenue is small, then in this case management is poor or ineffective, which is equivalent to having a high level of uncertainty. And vice versa, if with small investments in management we get large revenue, then we have efficient management, which is equivalent to a low level of uncertainty. Therefore, the ratio of the values of $\mathrm{P}_{\mathrm{opr}}$ and $\mathrm{B}_{\mathrm{p}}$, first, determines not only the efficiency of enterprise management, but also serves as a measure of the uncertainty of its management.

It is to such situations that the magnitude of the entropy index H reacts, and therefore it is chosen as a measure of uncertainty. The correctness of this choice has been verified by practice and the correctness is confirmed by practical results presented in the scientific literature $[16,21,22]$.

We transform equation (3) to discrete form, writing it in the form of the relation:

$$
d H=H_{i+1}-H_{i}
$$

If we take approximately that $d t=1$ year, then we get:

$$
H_{i+1}=H_{i}+P_{o n p_{i}} \cdot H_{i}-B_{p_{i}} \cdot H_{i}^{2}
$$

The resulting equation (7) can be used to analyze the dynamics of the change in the value of the uncertainty of the state of the system under the influence of two competing factors, for example, such as the cost of control Popr and the result of the implementation of these costs $\mathrm{Bp}$. The averaged values of the entropy $\mathrm{H}$, calculated by the formula (9) are given in table 1.

Table 1. Dependence of the values of $\mathrm{H}$ by years.

\begin{tabular}{|c|c|c|c|}
\hline Years & $\Delta$ Popr & $\Delta$ Exp & Value H \\
\hline 1 & 0,2912 & 0,0916 & 0,05 \\
\hline 2 & 0,0584 & 0,0370 & 0,06 \\
\hline 3 & 0,2701 & $-0,0490$ & 0,07 \\
\hline 4 & $-0,1273$ & $-0,2592$ & 0,17 \\
\hline 5 & $-0,5649$ & 0,3354 & 0,08 \\
\hline 6 & $-0,3992$ & 0,1029 & 0,10 \\
\hline 7 & 0,0226 & 0,0466 & 0,12 \\
\hline 8 & 0,3375 & 0,0386 & 0,13 \\
\hline
\end{tabular}




\begin{tabular}{|l|l|l|l|}
\hline 9 & 1,3467 & 0,1114 & 0,13 \\
\hline 10 & $-0,2633$ & 0,2095 & 0,19 \\
\hline
\end{tabular}

The level of uncertainty $\mathrm{H}$ tends, albeit non-monotonic, to increase the chaos of external influences, and the value of $\mathrm{H}$ is an indicator of this chaos. In conditions of growth in the value of $\mathrm{H}$ of financial and economic indicators, enterprises must adequately respond to this uncertainty. As noted above, we observe a similar reaction in the foreign exchange and stock markets.

The analogy of the behavior of the car market with the stock and foreign exchange markets is due not so much to the scale and transience of the processes, but to the presence of uncertainty factors, taking into account which the management has to make a decision. It is the level of uncertainty that affects the dynamics of the market, and not the specificity of the goods sold.

\section{Models and Results}

The practical implementation of determining the change in the selected financial and economic indicators (FEP) was carried out according to the following algorithm:

- collection of initial data from annual reports of enterprises of one industry with their subsequent analysis and sorting;

- calculation of selected financial and economic indicators,

- calculation of the uncertainty value Hk for each k-th enterprise by years;

- calculation of the average level of uncertainty for the entire selected population of enterprises;

- construction of graphs of the dynamics of uncertainty both for each enterprise and for the industry as a whole;

- calculation of derived financial indicators for each enterprise;

- averaging the values of derivatives for the entire set of enterprises under consideration;

- analysis of the results obtained and preparation of conclusions and recommendations for their practical application.

To analyze and confirm the above assumptions, 4 enterprises of the Russian automobile industry were selected that produce the same type of products - mainly cars. Some of them additionally produce spare parts, minibuses, small trucks and other related products. These enterprises, and these are: AvtoVAZ (Togliatti), Avtotor (Kaliningrad), Izhavto (Izhevsk) and Volkswagen (Kaluga), are located in different regions of the Russian Federation and are socially and economically significant for the territories where they are based.

The analysis was carried out on the basis of accounting data and reporting of these enterprises for the period from 2012 to 2018, taken from the forms "Balance" and "Financial results". The financial statements of the enterprises were audited by the international company Ernst \& Young.

For the study, the following indicators from the balance sheet and financial results were used:

Revenue (abbreviated name "Vyr");

Equity capital (IC);

Net profit (NP);

Amount of current assets (OA);

Amount of assets (A).

Based on the selected indicators, the PWG indicators were calculated in accordance with the rules given in section 3 .

The obtained indicators of the PRG are evaluated for proximity to the values of the Fibonacci levels, which is carried out only if the level of external market uncertainty increases.

The desire for the values of the Fibonacci levels is explained by an empirical pattern associated with the fact that it is in the presence of strong market uncertainty that market 
participants tend to them, since after that, when the uncertainty is removed, it is easiest to make a 180 degree reversal in the price trend from the Fibonacci levels, i.e. e. move in the opposite direction.

So, if there is a growing (bullish) trend, which, with its growth, goes too far and thus falls into a certain zone of uncertainty, then for a faster return to a decreasing (bearish) trend, it is necessary to get as close as possible to the nearest Fibonacci level. Thus, in essence, Fibonacci levels are the points most favorable for performing a maneuver for maximum dynamics in the market.

The values of financial and economic indicators of the enterprise, depending on their smallness, "choose" one or another Fibonacci level, from which it will be easier for them to make a reversal in the future.

Thus, the task is divided into two parts:

- Assess the level of uncertainty, taking into account the market situation, which in this case may increase or decrease. The uncertainty level is estimated using the dynamic Verhulst equation (3), which can be represented as:

$$
(1 / \mathrm{H}) * \mathrm{dH} / \mathrm{dt}=\mathrm{A}(\mathrm{t})-\mathrm{B}(\mathrm{t}) * \mathrm{H}(\mathrm{t}),
$$

where $\mathrm{H}(\mathrm{t})$ is the value of entropy, as a classical measure of the level of uncertainty;

A ( $t$ ) is a value that increases entropy (for an enterprise it can be the amount of administrative expenses, it is selected from the form "Financial results");

$\mathrm{B}(\mathrm{t})$ - the company's revenue (selected from the "Financial results" form).

As a result, in the Verhulst equation, the uncertainty value $\mathrm{H}(\mathrm{t})$ reacts to two indicators as follows:

- If the revenue is large, and the management costs are small, then in this case the external environment does not represent a significant value; it is small.

- If the costs of management are large, and the revenue is small, then in this case there is a significant uncertainty in the external environment, and it interferes with quality management.

This "competitiveness" of the two factors indirectly reflects the level of assessed uncertainty in the external environment. It is necessary to assess the degree of approximation of the PRG indicators to the Fibonacci levels for those time intervals when the value of the uncertainty $\mathrm{H}(\mathrm{t})$ increases.

If these two trends coincide, then we can say that the behavior of the financial and economic indicators of the enterprise in conditions of uncertainty obeys the laws characteristic of the foreign exchange and stock markets.

This conclusion, if it is confirmed, has not only theoretical but also practical significance. In this case, it is possible, using a unified methodology, to approach the assessment of actually different objects that fall into uncertainty conditions, and use this factor in control problems. Moreover, an extremely important aspect here is that the values of the PWG indicators can be calculated in advance and almost instantly used in a "trigger" mode in the event of various kinds of market uncertainties.

\section{Conclusion}

The results of the analysis, as well as literary sources, where similar studies are cited, indicate that the identified patterns of market behavior in conditions of uncertainty exist as an objective reality.

The obtained and the above results of studies of the technology of transition to the PRG regime give grounds to assert that this technology can be universal and serve as an effective 
tool for solving the problem of sustainable economic development of various economic agents, regardless of their scale and industry.

The presented scientific material is of practical value and can be recommended as guidelines for the management of not only automobile concerns, but also other large companies.

\section{References}

1. A.I. Ivanus. Cognitive methods and technologies of economic management in conditions of uncertainty (Prometheus, 2019)

2. S.O. Varygin, V.V. Agafonov, Mining Informational and analytical bulletin, 3, 3 (2019)

3. I. Popova. Management Decision-Making by the Head of the Peasant Farm Enterprise under Conditions of Uncertainty. IOP Conference Series: Materials Science and Engineering, 753, 062021 (2020)

4. O. Zoria, Black Sea Economic Studies, 46-1, 99(2019)

5. V. Mukoviz, I. Komarova, Prace Naukowe Uniwersytetu Ekonomicznego we Wrocławiu, 375, 86(2015)

6. N. Hazrati, IUI '20: Association for Computing Machinery, 21 (2020)

7. Satiani, Bhagwan et al, Journal of Vascular Surgery, (2020)

8. T. Bezrukova, S. Kirillova, F. Sattorov, A. Bazieva. Actual directions of scientific researches of the XXI century: theory and practice, 3, 27 (2015)

9. O. Kravchenko, M. Sypko, Efektyvna ekonomika, (2018), http://www.economy.nayka.com.ua/?op $=1 \& z=6754$

10. A.D. Prawitz, Ju. Cohart, Journal of Financial Counseling and Planning, 27, 142 (2016)

11. V. Shpil'ova. Proceedings of Scientific Works of Cherkasy State Technological University, 46, 21 (2017)

12. Jin, Hong et al., Wirel, 93, 81 (2017)

13. D. Ren, J. Du, Social Informatics and Telecommunications Engineering, 326, $315,(2020)$

14. D.V. Arutyunova. Strategic management (TTI SFU, 2010).

15. A.I. Bogomolov, A.I. Ivanus, V.P. Nevezhin, Vestnik of the research center of corporate law, management and venture investment of Syktyvkar state University, 1, 21 (2016).

16. A.I. Ivanus, Economics and Management: Problems, Solutions, 8- 7(68), 71(2017).

17. T. Ghose. What Is the Fibonacci Sequence? https://www.livescience.com/37470fibonacci-sequence.html

18. M.I. Bolos, I.A. Bradea, C. Delcea, Entropy, 22 (1) 121, 27 (2020)

19. S. Darda. Entropy and Economy.http://economicentropy.com/en.

20. A.K. Aylamazyan, E.V. Stas, Informatics and theory of development, (Nauka, 1989) 
21. K. Jurado, S.C. Ludvigson, S. Ng, American Economic Review, 105 (3), 1177 (2015).

22. A.V. Sigala, The use of entropy in modeling decision-making processes in economics. (ODZHAK, 2013) 